\title{
FIBROSITIS: SOME OLD AND NEW POINTS OF VIEW
}

\author{
BY C. W. BUCKLEY
}

Since the word fibrositis was proposed by Sir William Gowers to cover acute lumbago, brachial neuritis and similar conditions, it has come to be very loosely applied and now covers as wide a field as does the word arthritis in the minds of the general public. Stiffness and pain are the distinguishing characters, but vary in degree and their relation to each other: pain may be slight or even absent, and stiffness varies from muscle spasm, or limitation of movement due to fear of arousing pain, to actual contraction of capsular ligaments or adhesions between muscles and other tissues. Critical examination of the current views on the ætiology and pathology seems to be overdue, and an attempt might be made with advantage to discover the relation, if any, between such forms as the lumbago of acute onset and short duration and the chronic degenerative processes seen as a result of overuse in some occupations or even as a mark of advancing years.

It is worth while to recall the description given by Gowers (1904) when he first suggested the name fibrositis. He gave an admirable clinical account in which he says that there is no indication of the formation of inflammatory products, but admits that this is not enough to justify a denial of its inflammatory nature. $\mathrm{He}$ pointed out that the pain of lumbago is felt in the afferent nerves, which terminate in the interstitial tissue between the muscle fibres and not on the muscle fibres themselves as do the efferent nerves; the only ending of these afferent nerves is in the bodies called the muscle spindles. These structures appear to belong to the fibrous tissue which sheathes and connects the muscle fibres and not to the muscle itself. They are long structures lying between the muscle fibres; one or more muscle fibres enter each, and two or more nerve fibres, usually one at each end and one in the middle, where they divide and ramify. Normally they give rise to no sensation, and pain, when it occurs, is due to excessive excitation or to an induced excessive sensibility; 
it may be caused by compression of the muscle or the adjacent fibres to an undue degree. Fibrositis tends to spread by continuity of tissue, especially to tendinous structures, which themselves contain nerve endings resembling the muscle spindles and consist of an interlacement of nerve fibres enclosed in a capsule, but they are not elongated in shape and contain no muscle fibres; they are sensitive to strain or compression. Gowers described the so-called brachial neuritis as being similar in nature to lumbago but different in seat; the pain arose, he believed, in the muscles and was induced by their contraction or by sudden tension however slight; attempt at movement induces pain so severe that an involuntary contraction of the muscle occurs immediately, fixing the shoulder joint so that the parts appear to be fixed by adhesions.

It is to be noted that Gowers did not attribute the pain of fibrositis to implication of nerves in the inflamed connective tissue but to the sensory function of the muscle spindles and the similar structures in tendons, and it may be presumed in ligaments also. Nor does he mention the idea so frequently suggested that pain may be due to pressure of a nodule on a nerve fibre which has always appeared to me entirely unsupported by what is known of sensory function. Pressure on the specialised nerve endings whose function is the conveyance of pain sensations may naturally cause pain, but the effect of pressure on a nerve fibre or trunk is not to produce pain of the type characteristic of rheumatism but a "pins and needles" sensation referred to the area of distribution of the nerve, such as is familiar to everyone as the result of pressure on the ulnar nerve at the elbow. Gowers' observations on the function of the muscle spindles appear to be supported by the work of Lewis and Kellgren on referred pain resulting from muscle lesions.

The idea that low-grade inflammation of the connective tissues explains the pathology of fibrositis is hardly adequate, for the cardinal symptoms of inflammation are never marked and often absent. Poynton and Schlesinger define fibrositis as a pathological process underlying various rheumatic disorders both of a chronic and an acute nature. It is a reaction of the cells of the white $\stackrel{N}{\circ}$ fibrous tissue which may result from trauma, chill, " allergy," " toxæmia, either metabolic or bacterial, or actual bacterial invasion. This definition is wide enough to cover all the possible forms, for ${ }^{\sigma}$ under the heading Fibrositis are included conditions as diverse 
in ætiology, pathology, and clinical course as are acute rheumatoid arthritis and "malum coxæ senilis."

We owe to Professor Stockman the most complete description of the histological appearances as they are met with in the superficial fibrous tissues and the aponeuroses. He has described inflammatory hyperplasia in larger or smaller patches with numerous fibroblasts, serous or sero-fibrinous exudation, thickening of the walls of the small bloodvessels and nerve sheaths. This description is obviously based on the examination of affected tissues at a later stage and is probably not applicable to the acute stage of lumbago or brachial neuritis with which Gowers was concerned. These changes affect small patches of the fibrous tissues, organisation takes place with the formation of nodules, plaques, and strands of thickened tissue, and adhesions between adjacent structures. These formations are persistent and are apt to be sensitive to barometric changes, dietetic indiscretions, and other influences, and are characteristic of the chronic rheumatic subject.

In view of the scepticism often expressed as to the importance of nodules in the diagnosis and treatment of fibrositis, and the doubts which appear to be entertained, especially in America, as to whether fibrositis is in fact a clinical entity, the point demands further consideration. It has been said that the nodules of fibrositis are perceptible only to the finger of faith, and that they are structures which the physician discovers but the scalpel of the surgeon fails to reveal. It is my own opinion that their importance has been exaggerated. They are common enough, but probably more often symptomless than otherwise. They may be palpated in the superficial fibrous tissues of the buttock, especially just below the iliac crest and in other places in people who have never had any symptoms. Such nodules are painless unless pressed firmly against the underlying bone, which might be expected to cause pain even in normal people; quite frequently small masses of fat are regarded as fibrositic nodules. Attempts to break down nodules of this kind by hard massage are futile and must result in trauma and fresh nodules. Quite different are the localised thickenings in the substance of the muscles, which appear often to be due to binding together of adjacent muscle fibres and spindles by adhesions, the result of earlier inflammatory or allergic attacks, or to local areas of muscle spasm, and these will yield to massage properly applied, which will break down the adhesions, liberate the muscle fibres, and result 
in the relief of symptoms. I think it has yet to be demonstrated that a local patch of fibrous tissue, however organised in structure, will give rise to symptoms unless it implicates the muscle spindles or other nerve end organs, or sets up tension between adjacent muscle bundles. These thickenings in the substance of the muscle are usually ill-defined and often difficult to detect, but are generally extremely tender; their importance is less from the point of view of diagnosis than as a guide to the site at which injection of local anæsthetics is likely to have a beneficial effect.

An observation of great importance is that of Gratz (1937), who states that the fascial surfaces of muscles are, like tendons, covered with a layer of mesothelial cells, a functional adaptation of the fascial planes, facilitating movements between the groups of muscles they enclose, thus forming "joints" between the muscles. Fascial adhesions may thus be the cause of pain and limitation of movement, but these symptoms may also result from any interference with the nutrition of these mesothelial cells and their function-in fact, such circumstances as may give rise to synovitis of a joint or tendon sheath, whether dry or accompanied by effusion, which under favourable conditions will clear up without the formation of adhesions. Localised spasm of muscle fibres in the neighbourhood is likely to result, and a nodule or an area of increased resistance may be felt on palpation. This will be associated with pain on attempted movement, but the symptoms will usually clear up completely with suitable treatment or even with rest alone. The crepitus so often met with in the neck apart from any pain or marked stiffness, and which is apt to be attributed to arthritis of the cervical spine, is due to friction between the muscles themselves and adjacent structures and is very like the crepitus in the knees in villous arthritis.

The lymphatic circulation is intimately connected with the fascial spaces, and the fascia derives its nourishment from the lymphatics and not from the blood supply directly. It is important to note that lymph is not simply a transudation from the blood but differs from the plasma in chemical composition and is probably modified by the secretory activity of the tissue cells. It is possible, though difficult to prove, that this excretory activity is selective and eliminates from the blood stream toxic substances of certain kinds, including those of gout, which will exert a deleterious effect on the mesothelial cells. Similarly the result of a local lowering of temperature by exposure to cold, below that 
which is optimum for the tissue cells, will if prolonged be productive of pathological effects.

The development of bursæ and even of joints, in an earlier stage of existence, from fissures in the mesenchyme, links together bursitis and synovitis with fibrositis and the lymph in the connective tissue spaces with the synovial content of bursæ and joints, though the latter also contains mucin which appears to be secreted by the cells of the synovial membrane. I submit that a truer conception of fibrositis will be obtained if these points are borne in mind.

The close association of bursitis with other forms of fibrositis is seen in the periarthritis of the shoulder often miscalled brachial neuritis. In this condition we may have an inflammatory condition, sometimes infective in origin, of the fibrous septa of the deltoid muscle spreading to adjacent fibrous structures such as the ligaments of the shoulder joint, the tendons of the supraspinatus, and other muscles, and the subacromial bursa. Or, generally as a result of trauma, acute or chronic, we may find the bursæ primarily affected or the supraspinatus tendon may be frayed or ruptured. The result demonstrates all the characteristic features of fibrositis, especially the muscle spasm in the early stages, the formation of adhesions later, and the referred pain in the distribution of the musculo-spiral nerve so closely analogous with sciatica.

It is interesting to observe to what an extent the conception of a fibrositis of the sheath of the sciatic nerve or the brachial plexus has been abandoned as the referred nature of the pain has been more widely recognised. It would be advantageous to know how often an inflamed nerve sheath has been actually demonstrated by operation or at autopsy in cases other than cellulitis. I suspect that it is uncommon.

That gout may be the cause of fibrositis is denied by some and strongly held by others. Probably this depends on the diagnostic criteria regarded as essential in gout. If, as some hold, the presence of tophi is the only sound evidence of gout it must be admitted that tophi in the common situations are rarely seen unless typical attacks in the joints have occurred, and by no means always then. It would take too much space to argue whether this is a justifiable contention, but there is reason to believe that deposits of biurate of soda occur in other tissues than the cartilages of the ear or the joints or similar sites, and in proof 
of this the frequency of gouty deposits in the olecranon bursa may be quoted. If on the other hand a level of uric acid in the blood substantially higher than the normal is admitted as evidence of a gouty state, then gouty fibrositis undoubtedly often occurs.

In a series of cases under my own observation in which estimation of blood uric acid was carried out, in sixty-seven the amount found varied from $4 \mathrm{mg}$. per cent. up to 7.8; twenty-seven of these were diagnosed clinically as fibrositis; two had had typical gout in addition and showed tophi; thirty were diagnosed as arthritic gout; and the remainder were other forms of arthritis. The usual normal by the method used is 3.5 in women and 3.7 in men. From these figures, in addition to my own personal observation, I do not hesitate to say that fibrositis is frequently associated with a level of blood uric acid higher than normal, and I regard such cases as demanding treatment, both by diet and drugs, on the same lines as gout of the more orthodox type.

While the forms thus discussed are commonly due to trauma or toxins of bacterial or metabolic origin, the association of these causes with panniculitis is not obvious, and an endocrine factor seems more likely. There are grounds which would justify its separation altogether, for any link between acuteo lumbago or acute bursitis and the panniculitis of the postclimacteric type is difficult to find. Periarticular fibrositis is however, often met with in association with panniculitis.

Stockman (1926) has advanced the view that ossifying spondylitis, more usually termed ankylosing spondylitis, originates as a periarticular fibrositis, an important observation which has not received the attention it deserves. $\mathrm{He}$ recognises that ossification of inflamed fibrous tissue is rare, though it sometimes occurs in other conditions, and believes it is due to the fibrous tissue cells taking on the function of osteoblasts. I think there are many symptoms in ankylosing spondylitis, especially in the early stages, which present the characters of periarticular fibrositis, and the differences are less than those between spondylitis and rheumatoid arthritis. The question is one which certainly deserves further study.

\section{REFERENCES}

Gowers: Brit. Med. Journ., 1904, i. 118.

Stockman: "Rheumatism and Arthritis." Edinburgh, 1920.

Gratz: Arch. Surg., 1937, xxxiv. 471.

Stockman: Edin. Med. Journ., October, 1926, p. 597. 